\title{
WEATHER MONITORING STATION WITH REMOTE RADIO FREQUENCY WIRELESS COMMUNICATIONS
}

\author{
ISWANTO $^{1}$, HELMAN MUHAMMAD $^{2}$ \\ ${ }^{1}$ Department of Electrical Engineering, University of Muhammadiyah Yogyakarta, \\ Yogyakarta, Indonesia \\ ${ }^{2}$ Department of Electrical Engineering, University of Muhammadiyah Yogyakarta, \\ Yogyakarta, Indonesia \\ iswanto_tedumy.ac.id, helman.megmail.com
}

\begin{abstract}
Weather information is required before performing an activity, especially activities that directly relate to nature such as agricultural activities. Weather parameters are taken from the temperature, wind speed and solar radiation intensity. The system was designed with speed of optokopler as sensors, sensor LM35 as temperature sensor and sensor instensitas LDR as a measure of the sun. all sensors acquired by ATmega8535 microcontroller. The signal from the sensor is then processed and sent to the processor board to be translated into wind speed of the data parameter, temperature, and intensity of the sun. KYL $1020 \mathrm{U}$ used as an intermediary to transmit data from the processor board to the client computer.
\end{abstract}

\section{KEYWORDS}

Temperature, wind speed, solar intensity, weather station, AVR.

\section{INTRODUCTION}

Weather information is needed before performing an activity, especially activities that directly relate to nature such as agricultural activities. Agricultural activities may include determination of the schedule of planting, cropping patterns, planting, harvesting, processing of agricultural products to the transportation or distribution of agricultural products. Of weather information is expected to assist farmers in determining the time of planting and may set the pattern of plant species that are tailored to the needs of water for crops to be grown. Parameters are taken from the weather are temperature, wind speed and solar radiation intensity.

Research on the weather station have been carried out. Ardhiany Hastuti [2007] conducted a study on the Anemometer to measure temperature and humidity digital. System design on this tool, which consists of a series of wind speed sensor, temperature sensor, and humidity. Sensors are used as input to detect the speed ( $\mathrm{m} / \mathrm{s}$ ), temperature (0C), and air humidity (RH\%) and used as input to the microcontroller. The output of the microcontroller AT89S51 there are three kinds of data to be displayed to the LCD that is wind speed ( $\mathrm{m} / \mathrm{s}$ ), temperature (0C), and humidity (RH\%).

In addition, research related to temperature have been carried out. Ambar Tri Utomo [2011] conducted a study using a microcontroller ADC to measure the temperature eight-room. Amber has been successfully used ATMEGA8535 ADC using BASCOM language. 


\section{Proposed System}

Here is a schematic showing the process of data traveling from the sensor to be displayed on the computer. The design tool is broadly divided into two units, namely the sender unit and receiver unit. Sender unit consists of a speedo sensor optocoupler wind, sensor LM35 as temperature sensor, LDR as a sensor measuring the radiation intensity of light, a microcontroller as the processing unit or control data from the sensors, RF transceiver Kyl-1020U as a data sender, receiver RF-1020U Kyl as receiving data, RS232 serial communications as well as the computer as a recorder and a data viewer.

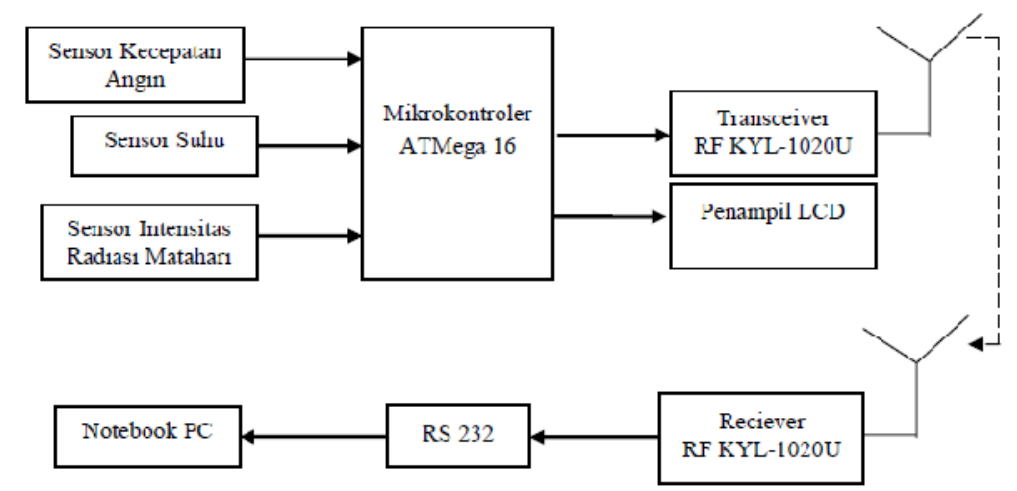

Figure 1 Block Diagram Tool Weather Station Telemetry

\section{HARDWARE DESIGN}

\subsection{Making Discs Encoder Template}

Template design is the image position of the hole-encoder disc hole. The holes will be made as many as 60 pieces, with the distance between holes $6^{\circ}$ obtained from the following calculation: The distance between holes $=360^{\circ} /$ number of holes

$$
=360^{\circ} / 60^{\circ}=6
$$

Here is a picture generated templates:

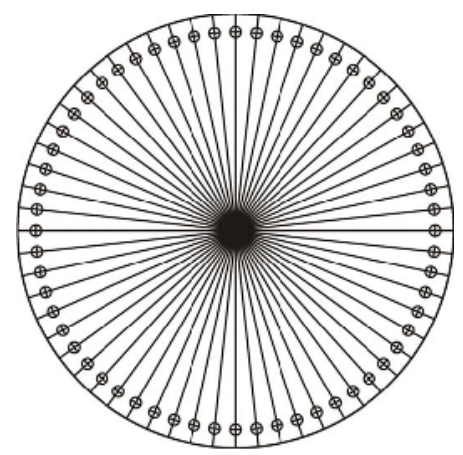

Figure 2 Template Encoder discs on CD-ROM $8 \mathrm{~cm}$ diameter 
Copyright sized $8 \mathrm{~cm}$ discs on top. The holes are made of $3 \mathrm{~mm}$ gap light with a skylight into account the optocoupler H21A2 $1 \mathrm{~mm}$ and also the availability of the drill bit to punch discs.

\subsection{Design Wind Speed Propellers}

Mechanical measurements of wind speed in the form of a propeller comprising 3 fruit bowl mounted on the radius centered on the vertical axis or all of the bowl is mounted on a vertical axis. Entire bowl facing a circumferential direction so that when the wind blows the rotor rotates on a fixed direction. Rotational speed of the rotor depends on wind speed. Plate sensor is a device used to sense the speed of rotary vane bowl. The focal point of the sensor plate and the center of the propeller bowls connected by a shaft, so that the disk rotation speed same as the rotational speed sensor vane bowl. Form of sensor plate is fitted with a propeller is shown in Figure 3 above.

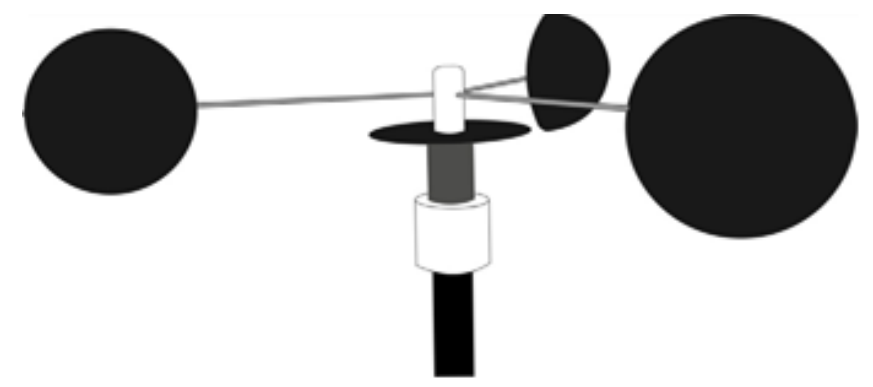

Figure 3 Design wind speed propeller

\subsection{Wind Speed Sensor Signal Crafts}

Photointterupter output signal pulses which are formed photointterupter light emitters due to the cut due to the holes encoder disc.

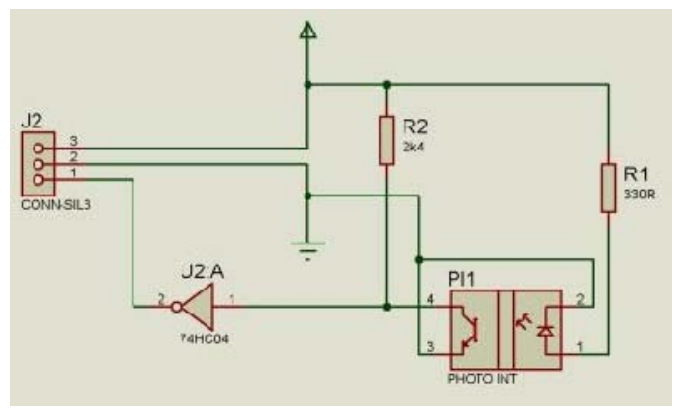

Figure 4 The circuit schematic signal tire optocoupler

Optocoupler output signal of the voltage pulses will not be stabilized through the gate so that the output voltage reaches 5V TTL level. To dole 74ls04 and optocoupler IC used positive voltage regulator with input voltage of $12 \mathrm{~V} 7805$ generates $5 \mathrm{~V}$ output voltage. Capacitors used for voltage stabilizer. R1 is used to limit the current to the optocoupler emitter while a pull-up resistor R2. 


\subsection{Temperature sensor circuit}

At design time, we use a sensor with a type of IC. Sensors of this type is divided into two options, namely the series LM34, and LM35 Fahrenheit scale, the Celsius scale, as in Indonesia is more familiar with $\mathrm{C}$, then we use the IC LM35. The working principle of the ambient temperature sensor IC is detected using the IC are sensitive to temperature, then temperature is converted into voltage by a circuit in the IC, where the temperature change is proportional to the change in output voltage. In the IC LM35 series $\mathrm{V} 0=10 \mathrm{mV} /{ }^{\circ} \mathrm{C}, 1^{\circ} \mathrm{C}$ change in output voltage results in a change of $10 \mathrm{mV}$. Has a temperature range of distances, between $-55^{\circ} \mathrm{C}$ to $150^{\circ} \mathrm{C}$, capable of operating between $4 \mathrm{~V}$ to $30 \mathrm{~V}$. The circuit is not complicated and does not require signal conditioning.

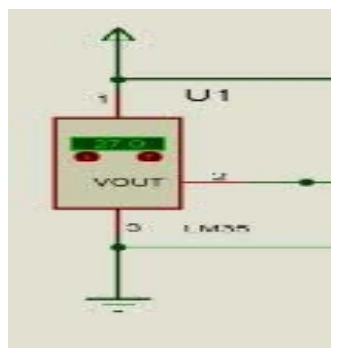

Figure 5 Schematic circuit Temperature Sensor

\subsection{The intensity of the light sensor circuit}

LDR sensor function to receive the intensity of light received from the sun. LDR resistance will change with changes in light intensity about it or around it. LDR resistance in the dark about $10 \mathrm{M}$ and the lucidity of $1 \mathrm{~K}$ or less. LDR is made from semiconductor materials such as cadmium sulfide. With this material the energy of light that falls cause more load is released or the electric current increases.

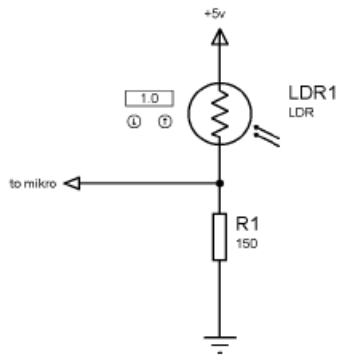

Figure 6 LDR sensor schematic

\subsection{The design of the controller circuit}

The controller circuit functions to process data from a series Optocoupler, LM35, and LDR data is processed by the ADC and interrupt features are contained in the ATmega16. The results of the $\mathrm{ADC}$ and the interrupt is what will processing software on a microcontroller to provide the final output, data output. This final will be sent serially to the computer by using IC max 232 or use distance transmission via radio frequency Kyl-1020U. 


\section{6. $\mathrm{RF}$ receiver module design $\mathrm{Kyl}-1020 \mathrm{U}$}

On J5 pin regulator circuit there is a main power supply of DC voltage of 12 volts of DC adapter that goes into IC voltage regulator then produces an output of 5 volts DC. Voltage of 5 volts is later used as a radio frequency power supply Kyl-1020U. J2 is the relationship TX-1020U Kyl RF receiver to the max232 IC T1 IN and from the entrance kePin2 T1 out RX male DB9 connector then after that the data can be displayed dikomputer. So the function of IC MAX232 is to change the voltage of the TTL level to RS232 level, because the radio used to use serial communication at TTL level RS232 level, while at the computer.

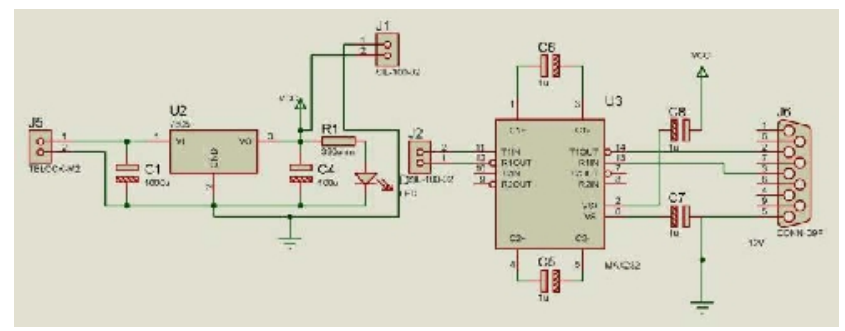

Figure 7 Schematic circuit module RF-1020U Kyl

\section{Flow Chart \& Calculation}

Design software for the weather station is made codevision AVR with a bunch of software programming using $\mathrm{C}$ language support These programs are designed to be incorporated into the microcontroller memory controller located on separate chain. To control circuits based mikrikontroler would require software that is integrated in the microcontroller chip. Before the program downloaded to the microcontroller program first created in CodeVision AVR programming software. After passing the test and the program as expected, then downloaded to the microcontroller program.

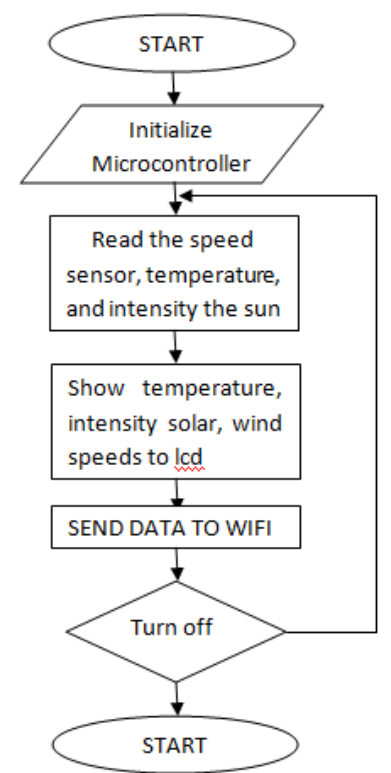

Figure 8 Flow Chart of Program 
International Journal of Embedded Systems and Applications (IJESA) Vol.2, No.3, September 2012

\section{Circuit Diagram}

The main components of the circuit above is the ATmega 16 controller that will receive data from the output of the LM35 sensors, signal conditioners Optocoupler, and LDR. These three sensors are connected to one port $\mathrm{ADC} 0, \mathrm{ADC} 1$ and INT2. Port $\mathrm{C}$ is used as the data path to the viewer on the LCD. X-tal used is $11.0592 \mathrm{MHz}$ x-tal lines of communication so that the error in the USART can reach $0 \%$. This microcontroller output to port facilities on the USART RXD danTXD will be linked to the Kyl-1020U radio frequency to transmit data and received by the radio frequency IC Kyl-1020U with 232 max uses to pin female DB9 serial data transmission to a computer. So that the output or display can be displayed on the computer.

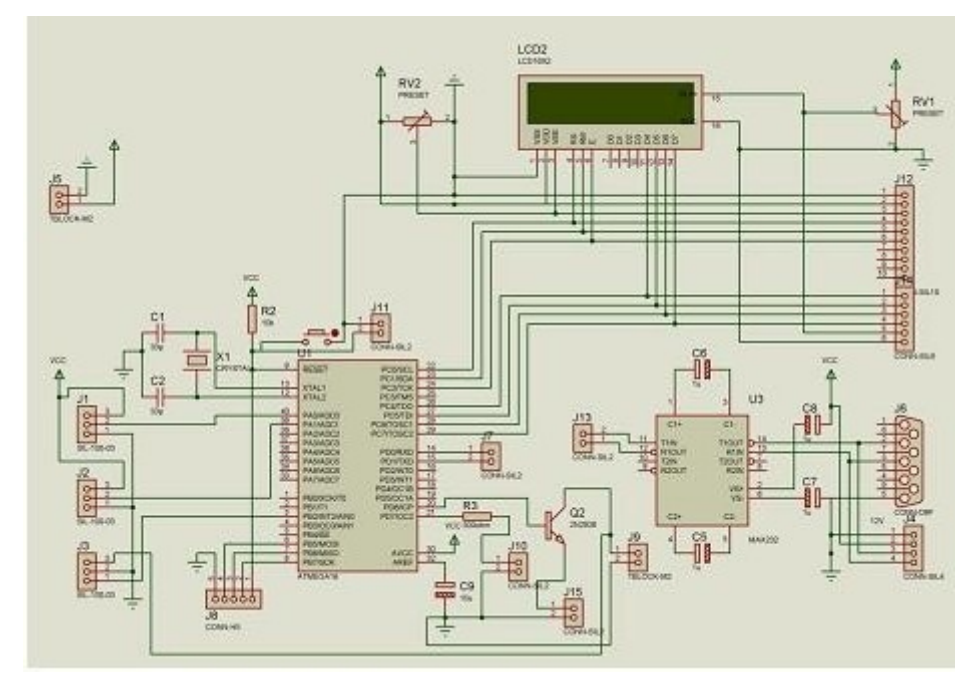

Figure 9 Schematic circuit controller

\section{RESULT}

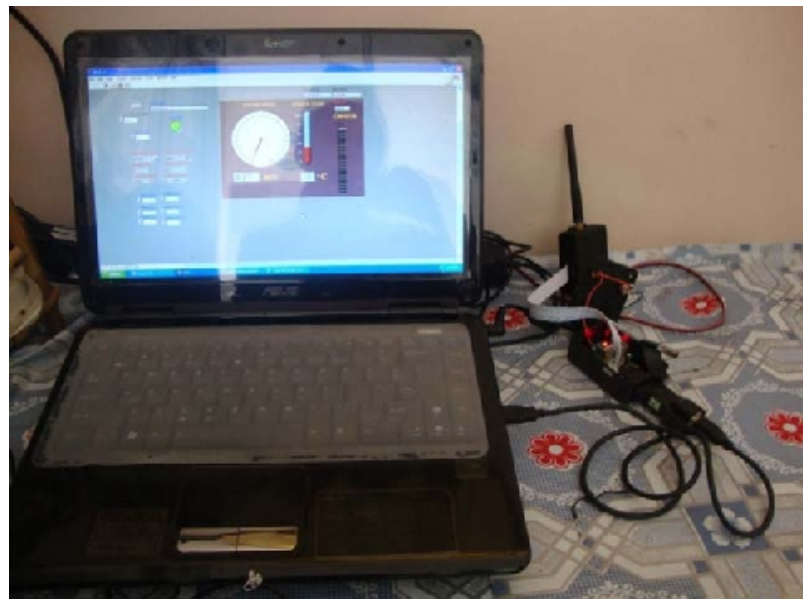

Figure 10 Radio Frequency Receiver Module series Kyl-1020U. 
International Journal of Embedded Systems and Applications (IJESA) Vol.2, No.3, September 2012

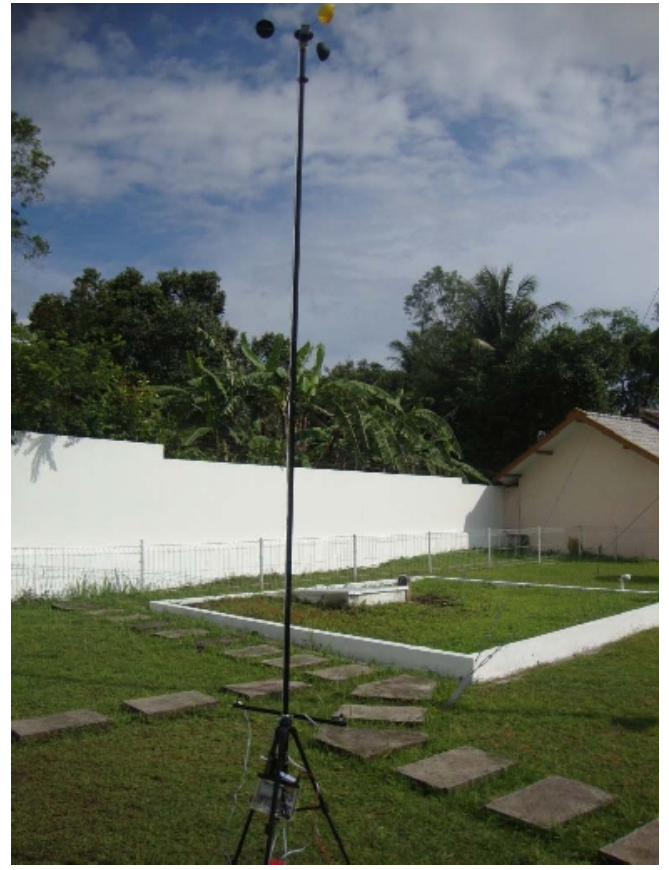

\section{CONCLUSIONS}

Figure 11 Tool weather stations

This tool serves as a Remote Weather Monitoring in real time by radio frequency wireless communications. The working principle of this instrument is from the sensor readings of wind speed, temperature, and intensity of solar radiation in units of each sensor and then the data is sent via radio frequency and the Kyl-1020U can didipantau via computer. Sensors used do not have resistance to vibration so if there is interference vibration sensor values can be changed.

\section{REFERENCES}

[1] Ambar Tri Utomo, Ramadani Syahputra ST, MT, ST Iswanto, M.Eng. Of 2011. Microcontroller implementation of Eight Rooms For Temperature Gauge. Journal of Technology Akprind. Vol. 4 No. 2. Yogyakarta.

[2] Ardhiany Hastuti, 2007, the design and manufacture of Anemometer with thermometer and humidity digital, Thesis Department of Electrical Engineering, University of Muhammadiyah Yogyakarta, Yogyakarta

[3] Iswanto, 2008, Design and Implementation of Embedded Systems Microcontroller ATMEGA8535 with the Basic language, Gava Media Publishers, London.

[4] Iswanto, 2008, Parallel Port and Serial Port Interface Compatible with Delphi 6 Opetrasi Window System, Gava Media Publishers, London.

[5] Iswanto, 2009, Learning Self AT90S2313 Microcontroller With Basic Compiler, Andi Offset Publishers, London.

[6] Mohammad Rifai Noor, 2012, Weather Stations Remote Monitoring In Real Time With Radio Frequency Wireless Communications, majoring in Electrical Engineering Thesis, University of Muhammadiyah Yogyakarta, Yogyakarta 
International Journal of Embedded Systems and Applications (IJESA) Vol.2, No.3, September 2012

\section{Authors}

Iswanto received his B.Eng. and M.Eng. degree in Electrical Engineering from Gadjah Mada University, Indonesia, in 2004 and 2009, respectively. Since 2009 he has been a lecturer in Electrical Engineering Department, Universitas Muhammadiyah Yogyakarta (UMY), Indonesia. His research interests include Robotics, Microcontroller application and the field of power electronics

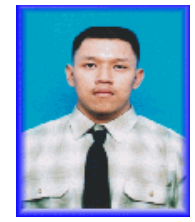

Helman Muhammad received his B.Eng. and M.Eng. degree in Electrical Engineering from Gadjah Mada University, Indonesia, in 1996 and 2001, respectively. Since 1999 he has been a lecturer in Electrical Engineering Department, Universitas Muhammadiyah Yogyakarta (UMY), Indonesia. His research interests include Robotics and Microcontroller application

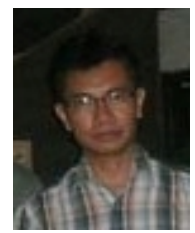

